\title{
Laser pressure welding of Al-Li alloy 2198: effect of welding parameters on fusion zone characteristics associated with mechanical properties
}

https://doi.org/10.1515/htmp-2020-0047

Received Jan 15, 2020; accepted Feb 19, 2020

\begin{abstract}
Al-Li alloy 2198 exhibits good combination of toughness and strength but its application is strongly limited by the poor weldability due to the formation of porosities during fusion-welding. This is the first study proposing and verifying a new approach to produce defect-free laser welds of poorly fusion-weldable Al-Li alloy 2198 with applied external pressure, i.e., feasibility of laser pressure welding to Al-Li alloy 2198 was examined. The microstructures associated with tensile shear behavior of laser pressure welded Al-Li alloy 2198 obtained at various welding parameters were analyzed. The results showed that formation of the welding defect in the weld could be successfully suppressed by applying laser pressure welding, even without shielding gas. Three microstructural zones, including the chill zone, the columnar zone and the equiaxed zone were observed in the fusion zone. Size of fusion zone and area fraction of porosities generally increased with increasing roller pressure and welding heat-input, and they dominantly affected the tensile shear behavior, including the peak load and the failure mode, of the weld.
\end{abstract}

Keywords: Laser pressure welding, Al-Li alloy, Porosity, Microstructural characterization, Mechanical properties

\footnotetext{
`Corresponding Author: Tianbo Zhao: Department of Materials Processing, Graduate School of Engineering, Tohoku University, Japan; Email: zhao.tianbo.s5@dc.tohoku.ac.jp Yutaka S. Sato: Department of Materials Processing, Graduate School of Engineering, Tohoku University, Japan Rongshi Xiao, Ting Huang, Jingquan Zhang: High-power and Ultrafast Laser Manufacturing Lab, Institute of Laser Engineering, Beijing University of Technology, Beijing, 100124, China
}

¿ Open Access. (c) 2020 T. Zhao et al., published by De Gruyter. (Cc) BY License

\section{Introduction}

The addition of lithium to aluminum alloys reduces the density and improves stiffness and strength $[1,2]$. Among various Al-Li alloys, the third-generation Al-Li alloy 2198T8 achieves the excellent mechanical properties including a better combination of improved formability, tensile strength and toughness compared to the previous two generations, and has been applied to important aircraft structures [3]. To further achieve the weight reduction of the aircraft structures, the welding of aluminum alloy (AA) 2198 should be employed to replace the traditional joining methods, i.e., riveting and mechanical fastening. Laser welding generally results in the higher flexibility, narrower heat-affected zone (HAZ) and higher welding speed than friction stir welding (FSW), meeting the demands of aerospace industry. Especially for manufacture of the components with complex shapes, laser welding could show the better flexibility than FSW requiring necessary constraints and fixture during welding [4]. One of the most critical issues during laser welding of AA 2198 is the formation of the welding defects including porosities and solidification cracking in the fusion zone due to the high $\mathrm{Li}$ contents [5-16], which strongly inhibits its application in the aerospace industry.

To produce sound laser welds of AA 2198 containing acceptably a few defects, many attempts have been made. Some methods to suppress formation of porosity, e.g., controlling the ambient humidity [12, 14], removing the oxide layer and surface contamination [5, 12], preheating the workpieces in vacuum condition before welding [13, 15], applying filler materials [9-11, 16], and so on, have been reported. However, they could not suppress formation of porosity sufficiently, even though the solidification cracking could be effectively prevented [9-16]. To effectively reduce number of porosities, resulting in sound laser welds of AA 2198, new methods should be explored. 
Table 1: Chemical composition of AA2198-T8 [wt.\%]

\begin{tabular}{ccccccc}
\hline Contents & $\mathrm{Cu}$ & $\mathrm{Li}$ & $\mathrm{Mg}$ & $\mathrm{Ag}$ & $\mathrm{Zr}$ & $\mathrm{Al}$ \\
\hline $\mathrm{AA2198}$ & $2.9-3.5$ & $0.8-1.1$ & $0.25-0.8$ & $0.1-0.5$ & $0.04-0.18$ & Bal. \\
\hline
\end{tabular}
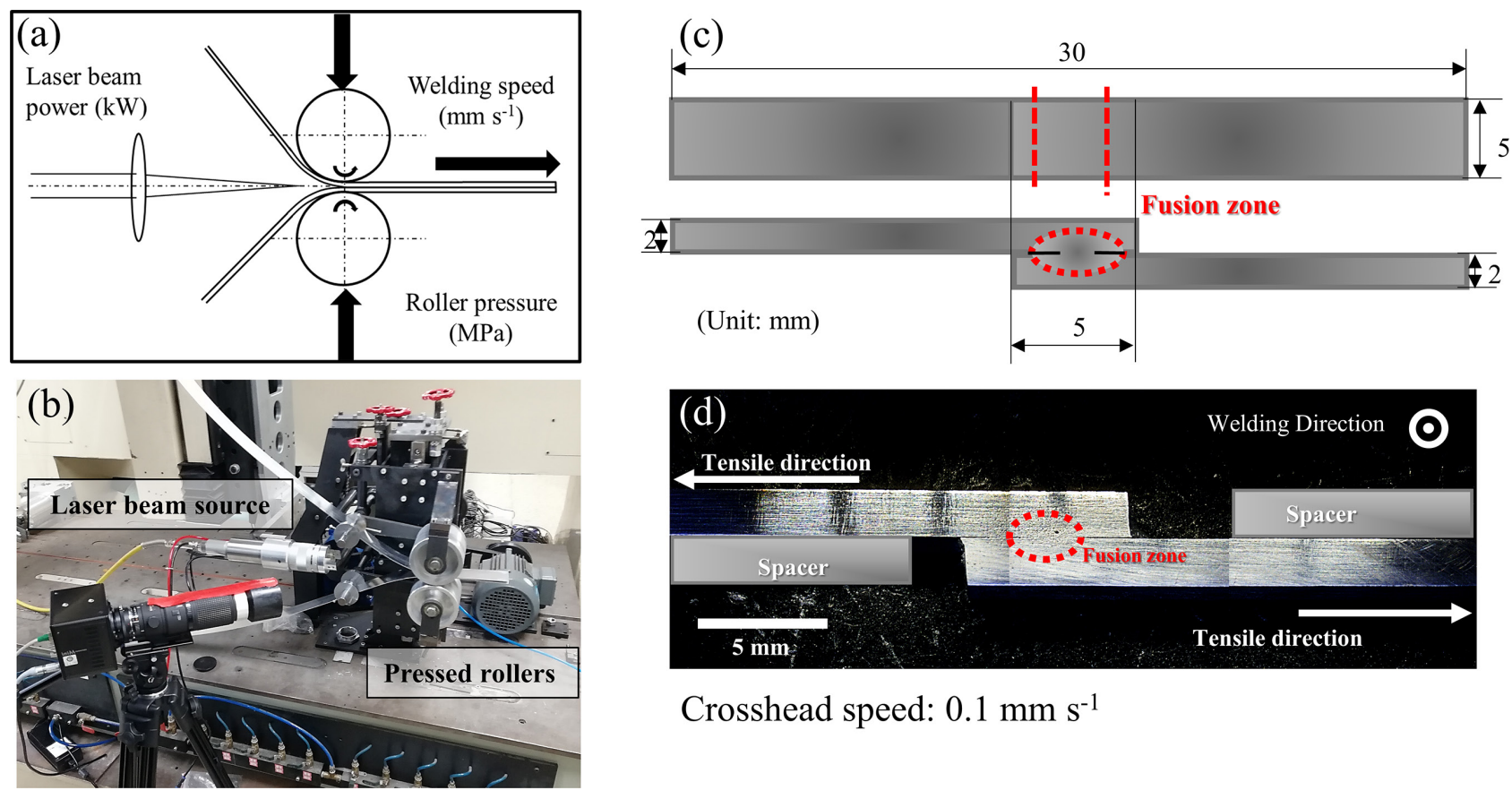

Crosshead speed: $0.1 \mathrm{~mm} \mathrm{~s}^{-1}$

Figure 1: (a) Schematic illustration of laser pressure welding; (b) experimental set-up of laser pressure welding; (c) Configuration of specimen for tensile shear test and (d) macroscopic picture of a tensile shear test specimen

Recently, laser pressure welding, a welding process simultaneously achieved by thermal effect of laser and mechanical effect of roller pressure [17, 18], which can apply external pressure to the weld pool during the solidification process of laser welding, has been applied to produce sound welds of pure aluminum [19]. In addition, the applied pressure exhibited some beneficial effects during solidification, such as increased solidification rate [20] and cooling rate [21], which could lead to refined microstructure [22] with fewer defects [23-28] and improved mechanical properties of the solidified alloys.

To apply this technique for making sound laser welds of Al-Li alloys, besides verification to suppress the porosity formation, formation mechanism of the fusion zone, and relationship between microstructure and mechanical properties of the welds should be examined. However, any attempts to produce defect-free laser welds of Al-Li alloy using laser pressure welding were not made, and the relationship between process parameters, fusion zone characteristics and mechanical properties has not been yet known.
The objective of the present study was to clarify the formation mechanism of the fusion zone during laser pressure welding and its effect on tensile shear strength of laser pressure welded AA 2198. In the present study, AlLi alloy 2198-T8 plates were laser pressure welded at various welding parameters. The characteristics of the weld fusion zones, including the size of fusion zone and the area fraction of porosities, were examined. Tensile shear tests were performed to evaluate the mechanical property of the welds. The relationship between welding parameters, fusion zone characteristics and tensile shear behaviors was also analyzed.

\section{Materials and Methods}

The base material used in the present study was aluminum alloy (AA) 2198-T8, $50 \mathrm{~mm}$ in width and $2 \mathrm{~mm}$ in thickness. Chemical composition of AA 2198-T8 is shown in Table 1.

The schematic illustration of the laser pressure welding process is shown in Figure 1. During the welding process, the limited surface areas on the overlapped interfaces 
of two workpieces are melted by a $6 \mathrm{~kW}$ YAG laser, and then the melted surfaces are pressed by 2 rollers to achieve sound joints. Table 2 shows the welding parameters employed. The welding heat-input $\left(\mathrm{J} \mathrm{mm}^{-1}\right)$ provided by the heat source is calculated with the laser power and the welding speed [16]. Due to the limitation of the equipment, the welding speed ranged from 73.3 to $250 \mathrm{~mm} \mathrm{~s}^{-1}$; the power output of the YAG laser ranged from 2 to $6 \mathrm{~kW}$; the roller pressure applied ranged from 0 to $200 \mathrm{MPa}$, meaning that the maximum welding heat-input of the used equipment was $81.9 \mathrm{~J} \mathrm{~mm}^{-1}\left(6 \mathrm{~kW} / 73.3 \mathrm{~mm} \mathrm{~s}^{-1}\right)$.

Table 2: Range of welding parameters

\begin{tabular}{ll}
\hline Laser power & $2-6 \mathrm{~kW}$ \\
Defocus distance & $0 \mathrm{~mm}$ \\
Travelling speed & $80-250 \mathrm{~mm} \mathrm{~s}^{-1}$ \\
Roller pressure & $40-200 \mathrm{MPa}$ \\
Welding heat input & $24.0-81.9 \mathrm{~J} / \mathrm{mm}$ \\
\hline
\end{tabular}

Followed by laser pressure welding, the specimens for the microstructure examinations were cut perpendicular to the welding direction, subsequently polished with $\mathrm{SiC}$ abrasive papers in water and then with diamond pastes. Finally, the specimen surfaces were prepared for $24 \mathrm{~h}$ in colloidal silica solution with a vibratory polisher. The specimens for macrostructure observation using optical microscopy (OM) were etched with Keller's reagent (a mixture of $1 \% \mathrm{HF}, 1.5 \% \mathrm{HCl}, 2.5 \% \mathrm{HNO}_{3}$ and $95 \%$ distilled water) at room temperature for $20 \mathrm{~s}$. The microstructures were observed by a Hitachi S4300SE scanning electron microscopy (SEM) equipped with an electron backscattered diffraction (EBSD) facility. Size of the fusion zone was quantified using SEM images of the 5 or more cross-sections of each weld, and the step size of EBSD measurement was $1 \mu \mathrm{m}$ at $25 \mathrm{kV}$. Compositional analysis of selected areas in the fusion zone was performed using electron probe microanalysis (EPMA) techniques at $8 \mathrm{kV}$ with a JEOL JSM-7800F SEM equipped with a field emission gun.

The strength of the AA 2198 laser pressure welds was examined by tensile shear testing. The specimens for tensile shear testing were cut perpendicular to the welding direction. 5 specimens for each material condition have been tested in order to achieve reliable results during tensile shear testing. The configuration and macroscopic image of the specimens are shown in Figure 1 (c) and (d). Tensile shear tests were performed on a screw-driven testing machine at a crosshead speed of $0.1 \mathrm{~mm} \mathrm{~s}^{-1}$ at room temperature.

\section{Results}

\subsection{Macroscopic examination}

In the ranges of the welding parameters, the appropriate combinations are necessary to produce the sound welds successfully. In fact, the combination of laser power and welding speed dominantly affected the formation of sound welds during laser pressure welding. Especially, lack of welding heat-input, caused by the high welding speed and insufficient laser power, resulted in the unwelded joints. To produce the sound welds in AA 2198, the laser power should be about $6 \mathrm{~kW}$. This shows that the minimum welding heat-input was approximately $24.0 \mathrm{~J} \mathrm{~mm}^{-1}$ to make the successful welds in AA 2198.

The typical cross-sectional overview of a laser pressure weld (heat-input: $81.9 \mathrm{~J} \mathrm{~mm}^{-1}$, roller pressure: 180 $\mathrm{MPa}$ ) and the enlarged image of the open rectangle are shown in Figures 2 (a) and (b), respectively. The fusion zone, shown by dash lines, is elliptical on the crosssection, as shown in Figure 2 (a). Only small amount of porosities was detected in the fusion zone. A crack along the lapped interface in the fusion zone is observed, as shown with the white arrow in Figure 2 (b). The formation mechanism of the cracks along the lapped interface in the fusion zone is not clear at present, but they would correspond to periphery of the melt pool that previously solidified before the workpieces were pressed by the rollers.

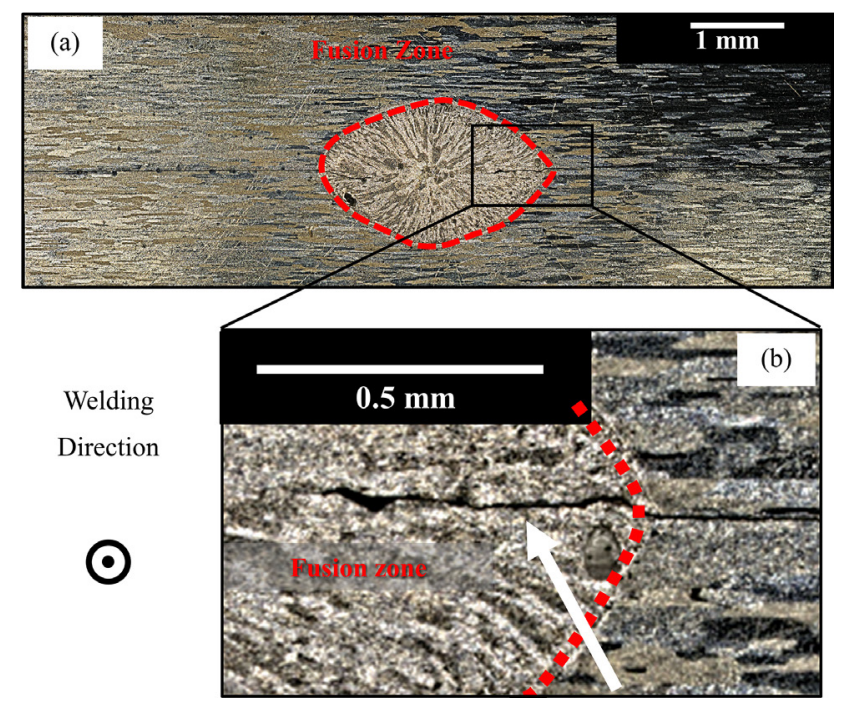

Figure 2: Macroscopic photographs of a laser pressure welded AA 2198. (a) OM image of the cross section cut perpendicular to the welding direction; (b) enlarged OM image of the unwelded region in the fusion zone. 

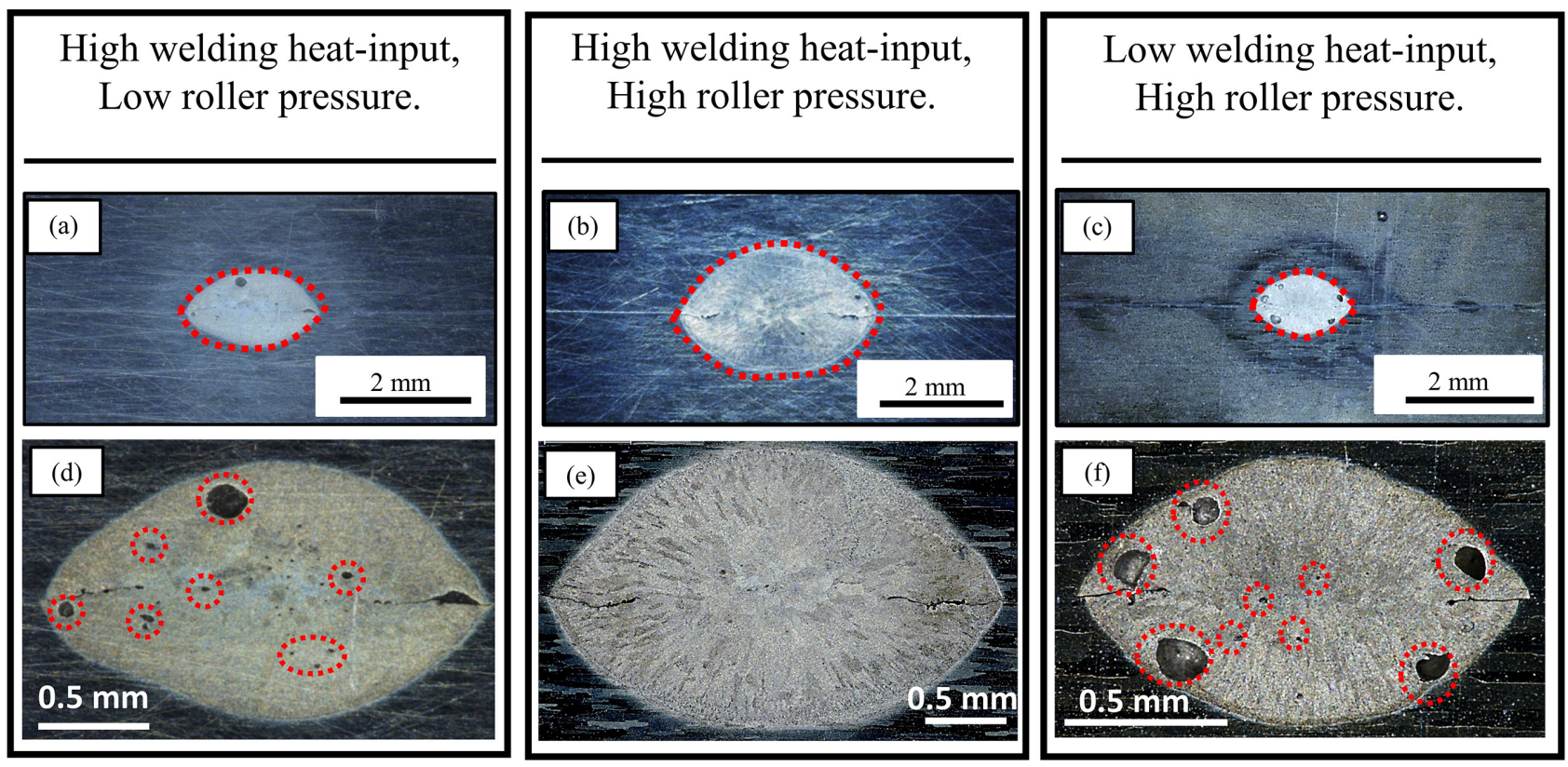

Figure 3: Macroscopic morphologies of fusion zones welded at various welding parameters: (a) heat input $\left(\mathrm{HI}\right.$, J mm $\left.\mathrm{m}^{-1}\right)=81.9$, roller pressure $(\mathrm{P}, \mathrm{MPa})=40 ;(\mathrm{b}) \mathrm{HI}=81.9, \mathrm{P}=180 ;(\mathrm{c}) \mathrm{HI}=54.6, \mathrm{P}=180$; (d-f) enlarged images of cross-sections shown in (a-c).

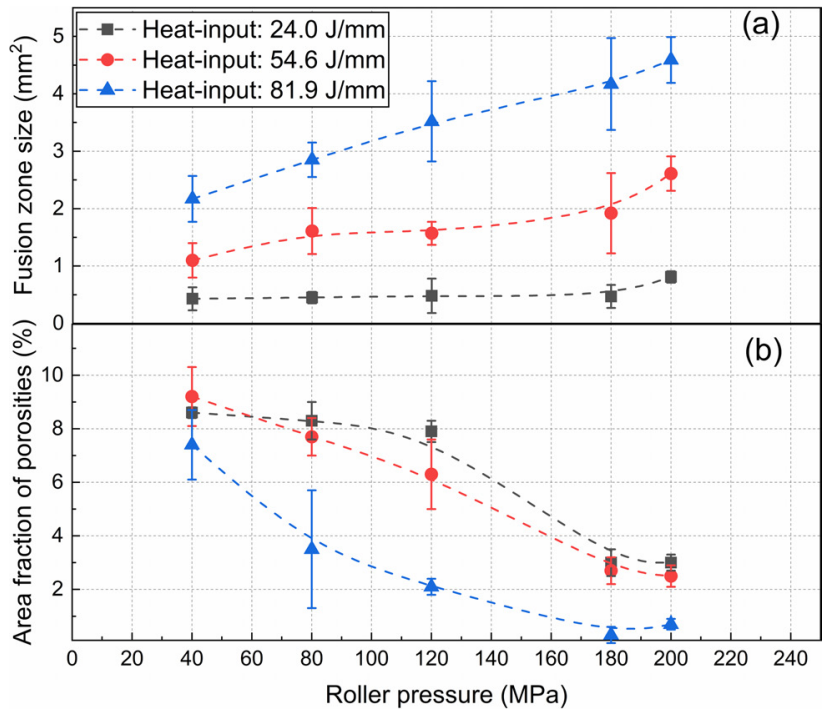

Figure 4: Effect of welding parameters on fusion zone characteristics: (a) effect of welding parameters on fusion zone size; (b) effect of welding parameters on area fraction of porosity in laser pressure welds.

The macroscopic overviews of the cross-sections of the welds obtained at various welding parameters are shown in Figures 3 (a) - (c). The higher welding heat-input and roller pressure resulted in the larger fusion zone. The relationship between the welding parameters, including roller pressure and welding heat-input, and the fusion zone size, is shown in Figure 4 (a). The fusion zone size clearly increases with increasing welding heat-input. The fusion zone size also increases with increasing roller pressure at high welding heat-inputs, but the variation in the fusion zone size is not significant at low welding heat-input.

As shown in Figures 3 (d) - (f), porosities can be found in the whole fusion zones, whereas those located closer to the fusion boundaries are larger, even though the formation mechanism of all porosities would be the same [3, 912]. These porosities have approximately spherical shape and isolated distributions, confirming the presence of gas bubble porosities $[3,10,11]$, while no evidence indicating the presence of shrinkage porosities has been observed. To evaluate the formed porosities in the fusion zone of laser welds qualitatively, the area fraction of porosities, which strongly affects the reliability of the weld [29,30], is often used. Effect of welding heat-input and roller pressure on area fraction of porosities in the fusion zone is shown in Figure 4 (b). Area fraction of porosities decreases with increasing roller pressure and welding heat-input. Area fraction of porosities was reduced from $7.4 \%$ to $0.1 \%$ at heat input of $81.9 \mathrm{~J} \mathrm{~mm}^{-1}$ when the roller pressure increased from $40 \mathrm{MPa}$ to $200 \mathrm{MPa}$. Acceptable area fraction of porosities (lower than 4\%) [31, 32] was achieved at the roller pressure higher than $120 \mathrm{MPa}$.

\subsection{Microscopic examination}

A combined image of backscatter electron (BSE) image (left) and EBSD orientation map (right) obtained from the 

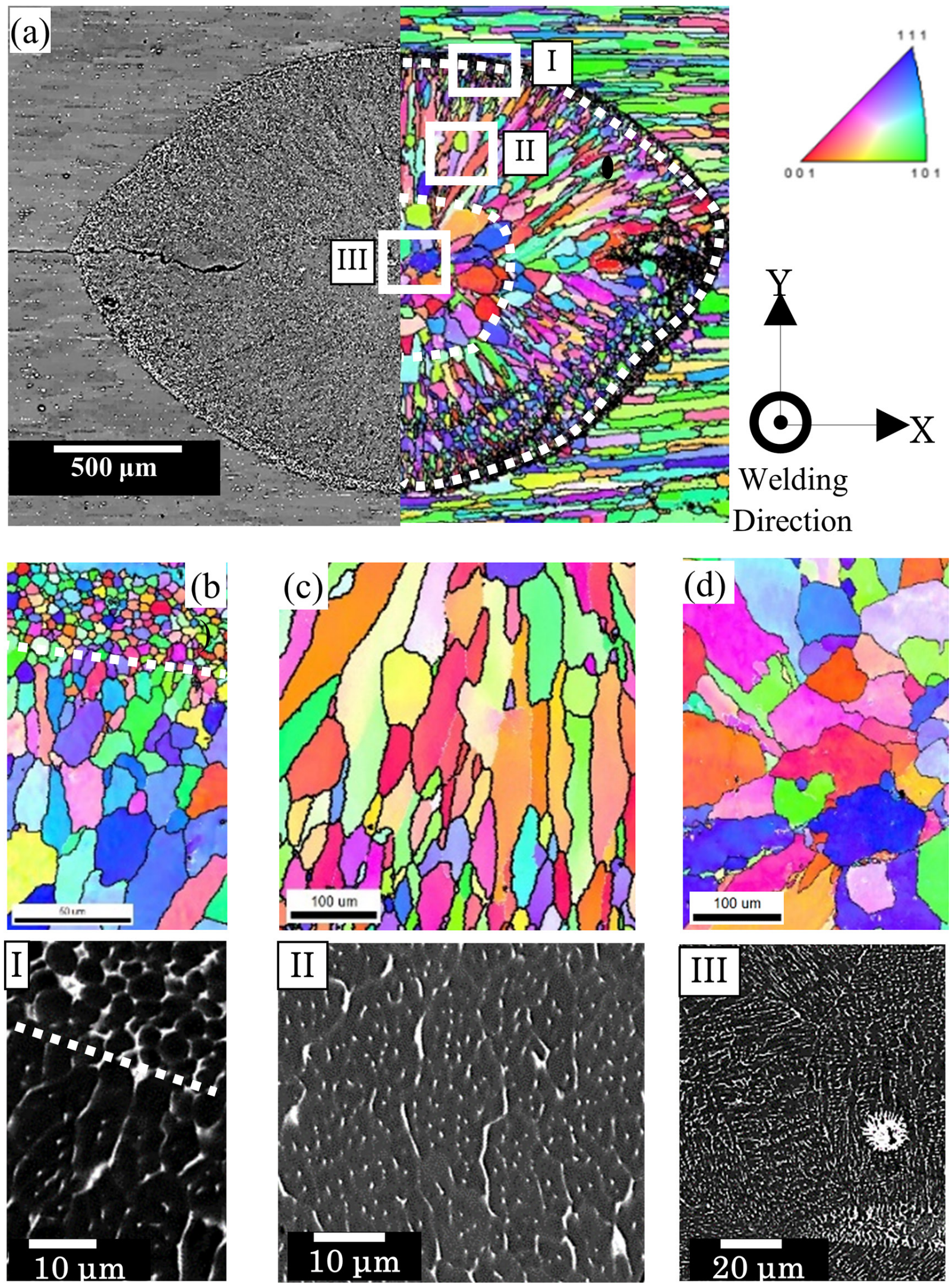

Figure 5: (a) Combined image of backscatter electron (BSE) image (Left) and orientation EBSD map (Right) of the fusion zone; (b) EBSD map of the chill zone (area I); (c) EBSD map of the columnar zone (area II) and (d) EBSD map of the equiaxed zone (area III). 


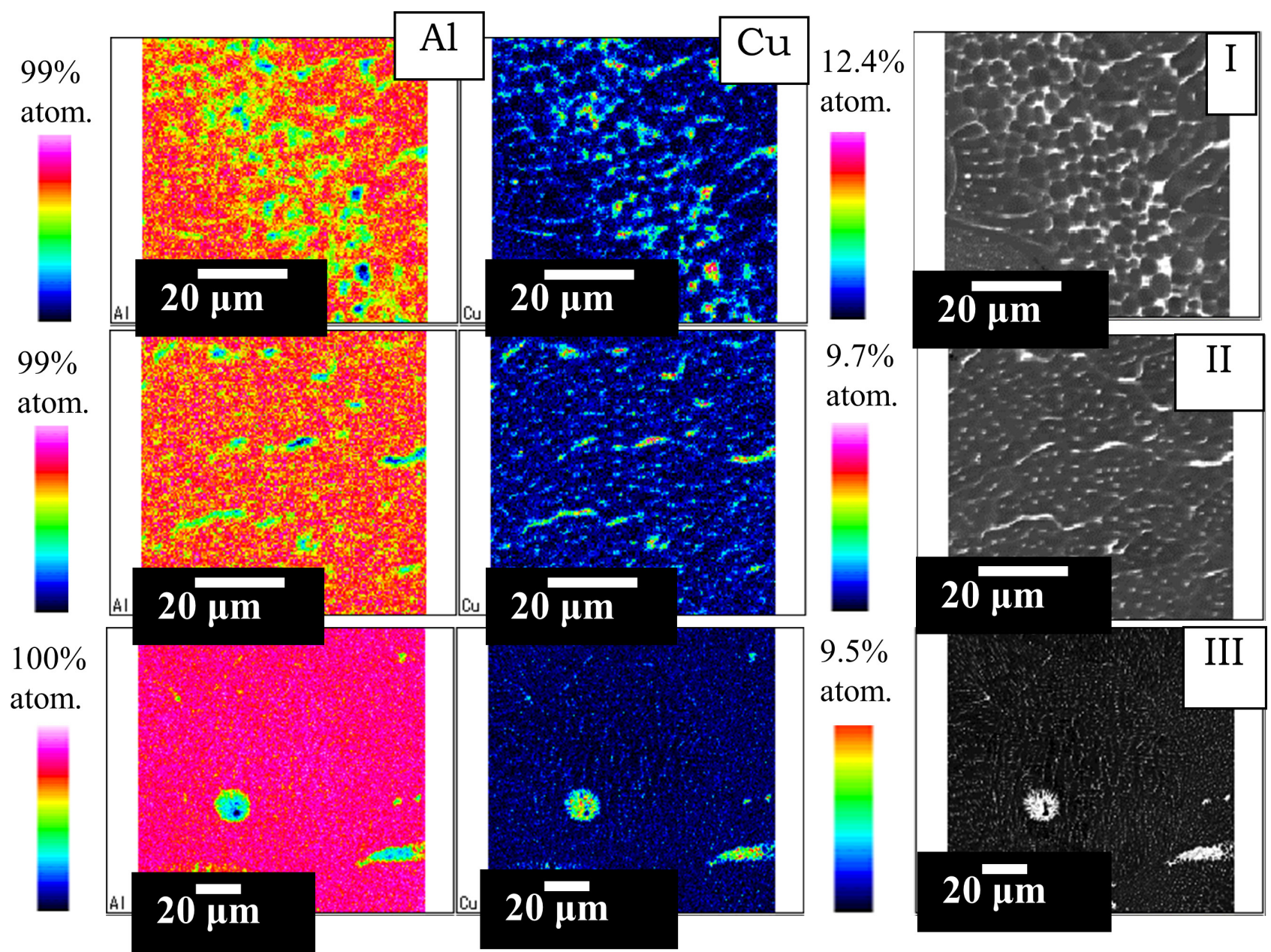

Figure 6: EPMA maps of Al and Cu (Left and middle) and BSE images (Right) of Area I, II and III.

cross-section was shown in Figure 5 (a). Based on the grain structure distribution of the EBSD orientation mapping, three distinguished microstructural zones, i.e., (I) the chill zone near the fusion boundary, (II) the columnar zone and (III) the equiaxed zone at the center of the fusion zone, can be observed. The chill zone (zone I in Figure 5a) consists of fine equiaxed cells (Figure $5 \mathrm{~b}$ ), was believed to form via a heterogeneous nucleation mechanism aided by some precipitates, e.g., $\mathrm{Al}_{3}(\mathrm{Li}, \mathrm{Zr}), \mathrm{Al}_{3} \mathrm{Ti}$ and $\mathrm{Al}_{3} \mathrm{Zr}$, which inhibit the epitaxial growth of columnar grains from the base metal, resulting in the formation of the thin layer of fine equiaxed cells [33-36]. The columnar zone (zone II in Figure $5 \mathrm{a}$ ), which is the dominant region located between the chill zone and the equiaxed zone in the fusion zone, is composed of large numbers of columnar structures (Figure 5c), which was formed due to the large temperature gradient near the fusion boundary [9-18, 23-26]. The equiaxed zone (zone III in Figure 5a), which consists of many equiaxed grains with well-developed secondary dendrites (Figure 5d), is located in central area of the fusion zone, resulting from the small temperature gradient [1216].

$\mathrm{Al}$ and $\mathrm{Cu}$ maps of three microstructural zones were analyzed by EPMA, and the corresponding BSE images (I, II and III correspond to zones I, II and III in Figure 5, respectively), are shown in Figure 6, to characterize solute segregation in the fusion zone, because severe $\mathrm{Cu}$ segregation has been commonly reported in the laser welds of AA2198 [9-18, 23-26]. These images showed that the high $\mathrm{Cu}$ content was detected in the grain boundaries in the chill zone (zone I), followed by the columnar zone (zone II) and the equiaxed zone (zone III), showing that the $\mathrm{Cu}$ segregation could be weakened from the chill zone to the equiaxed zone. Many studies on the microstructures of laser welds of Al-Cu-Li alloys [9-18, 23-26, 37] also reported that severe $\mathrm{Cu}$ segregation was detected in the chill zone, which is generally believed to be caused by degree of evaporation of low-melting temperature elements, such as $\mathrm{Al}, \mathrm{Li}$ and $\mathrm{Mg}$, i.e., low-melting temperature elements evaporate near the fusion boundary more easily than the fusion zone 


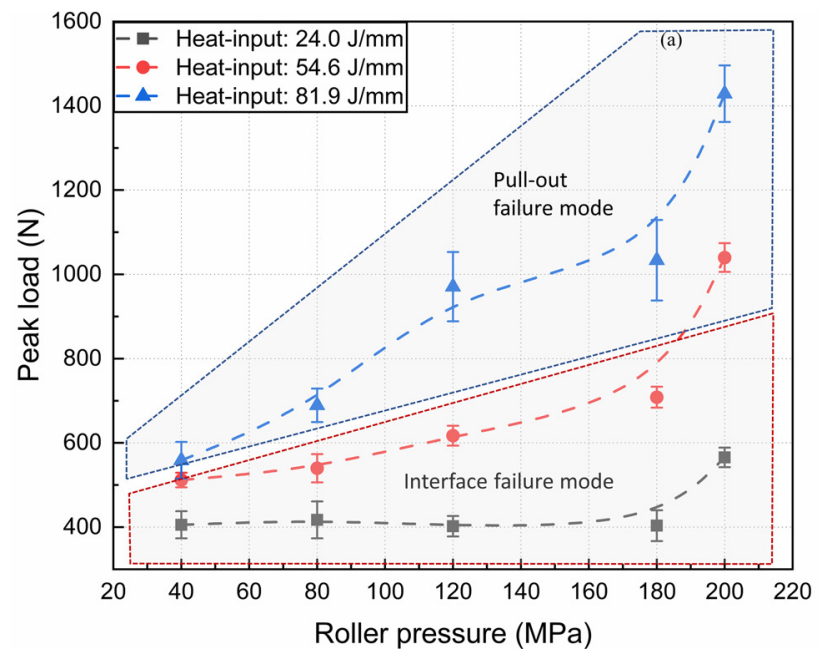

Figure 7: Effect of welding parameters on peak load of laser pressure welds during tensile shear testing.

center [30], resulting in the relatively high $\mathrm{Cu}$ segregation in the chill zone.

\subsection{Tensile shear test}

Figure 7 shows the peak loads (strengths) of the welds produced at various parameters during tensile shear testing. The peak load clearly increased with increasing welding heat-input. The peak load also increased with increasing roller pressure at high welding heat-input, but this effect is not significant at low welding heat-input. 2 different failure modes were detected in the specimens: the pull-out failure mode with fracture along the fusion boundary (Figure 8a), and the interface failure mode with fracture along the interface (Figure 8b). In the present study, the laser pressure welds exhibiting peak loads higher than $700 \mathrm{~N}$, which were mostly produced at welding heat-input higher than $54.6 \mathrm{~J} \mathrm{~mm}^{-1}$, failing in the pull-out failure mode. In the pull-out failure mode, the fracture propagated along the fusion boundary, as shown in Figure 8a, although there is a crack along the lapped interface in the fusion zone. In the interface failure mode, the fracture rapidly grows from tip of the crack along the lapped interface in the fusion zone to the fusion zone interior, as shown in Figure 8 (b).

\section{Discussion}

\subsection{The effect of roller pressure on the fusion zone size}

In the present study, the fusion zone size increases with increasing roller pressure at high welding heat-input. The reason for this effect is still unclear, but the enlarged fusion zone could be associated with the heat-dissipation promoted by increased roller pressure, because it is expected that the higher applied pressure would lead to the larger heat-dissipation from the fusion zone into the pressed rollers due to the intense contact between the workpieces and the pressed rollers [21, 23, 26]. In this case, the heat-affected zone proximal to the fusion boundary could be temporarily exposed to temperature higher than the melting point of AA2198, which could cause the enlarged fusion zone through the re-melting. Since the dissipated heat should increase with increasing roller pressure $[21,26]$, the fusion zone size increases with increasing roller pressure at high welding heat-input. At low welding heat-input, however, the dissipated heat is insufficient for the re-melting, so that the fusion zone size would be hardly affected by the roller pressure.

\subsection{Effect of welding parameters on formation of porosities}

The present study showed that the area fraction of porosities decreased with increasing roller pressure and decreasing heat input. Since porosities located adjacent to the fusion boundary were large, characteristics of the porosities located close to the fusion boundaries were compared in the weld produced at various welding parameters, as shown in Figure 9. The size of porosities decreased (Figure 9b) and finally closed (Figure 9c) with increasing roller pressure due to the mechanical pressing, which is in agreement with many previous studies [20-24, 26]. Moreover, deformed porosities are observed in the fusion zones of the welds obtained at the low welding heat-input $\left(24.0 \mathrm{~J} \mathrm{~mm}^{-1}\right)$ even though the roller pressure was high (Figure 9d). It is hypothesized that the lower welding heat-input causes the lower temperature in the fusion zone, resulting in the lower pressing effect on closure of porosities. Consequently, the area fraction of porosities increased with decreasing welding heat-input. 


\section{(a)}
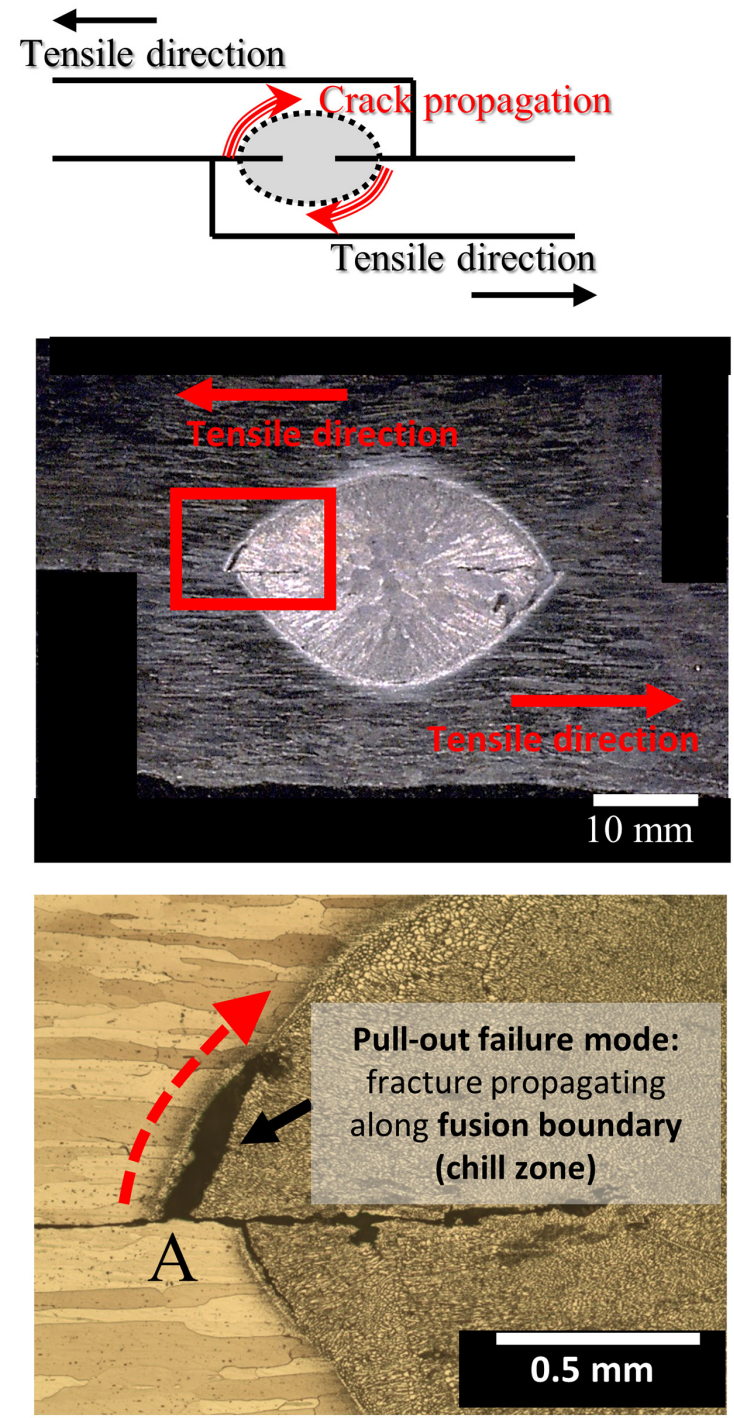

(b)

Tensile direction
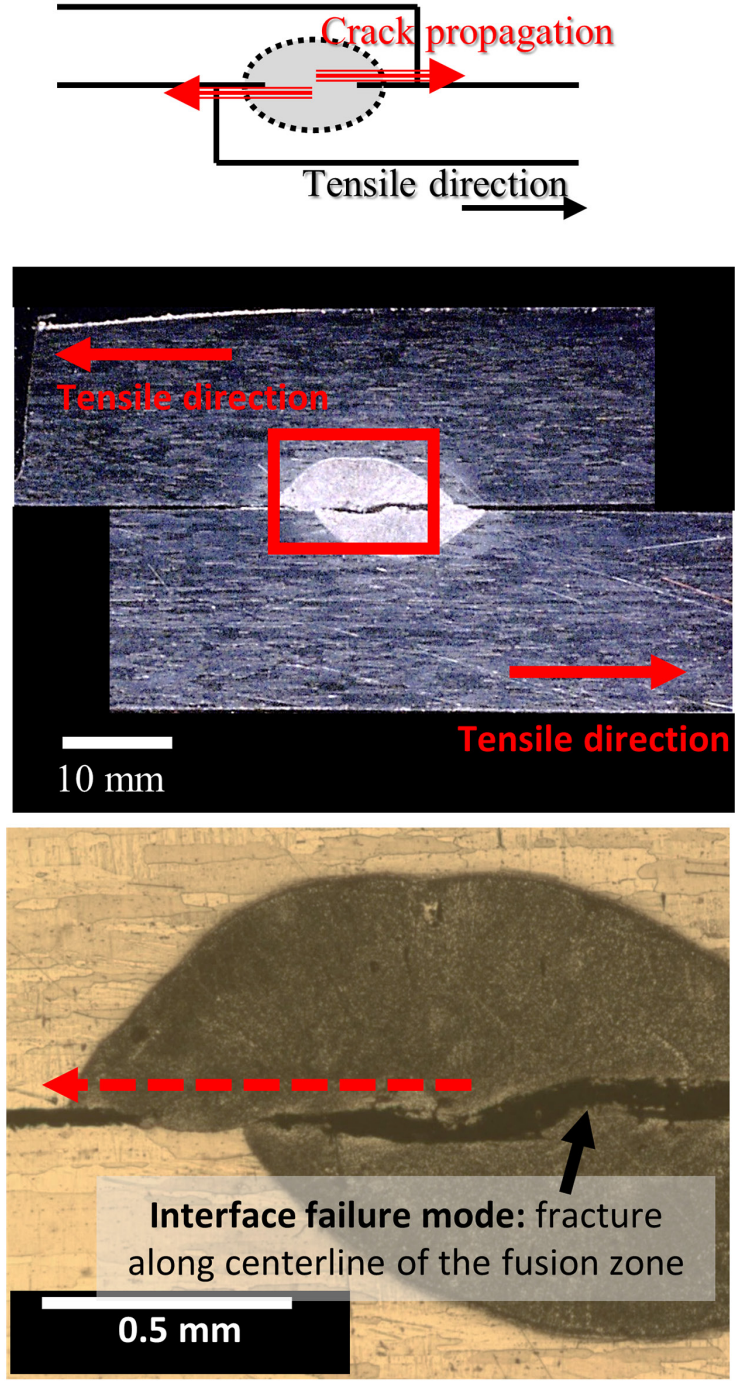

Figure 8: Detailed images of the tensile shear samples: (a) failed in pull-out failure mode; (b) failed in the interface failure mode.

\subsection{Effect of characteristics of weld fusion zone on tensile shear behavior}

The peak load of tensile shear test is affected by the welding parameters, but it should depend on the characteristics of the fusion zone, including the size and area fraction of porosities in the fusion zone fundamentally $[29,30]$. In this study, a correlation between the peak load of tensile shear test and fusion zone size was examined, as shown in Figure 10. The peak load clearly increased with increasing fusion zone size. Moreover, the welds having similar fusion zone sizes exhibited the higher peak loads at the lower area fraction of porosities. This study implies that the fusion zone size largely contributes to the peak load compared to area fraction of porosities.

The pull-out failure mode generally provides the higher peak loads and energy absorption than the interface failure mode [29]. The previous studies reported that the fusion zone size dominantly affects the failure mode of tensile shear tests of the welds $[29,30]$, i.e., an increase in fusion zone size changes from the interface mode into the pull-out mode. The welds having the fusion zone size larger than $2.5 \mathrm{~mm}^{2}$ failed in the pull-out failure mode. A preliminary multiple regression analysis of the data was 

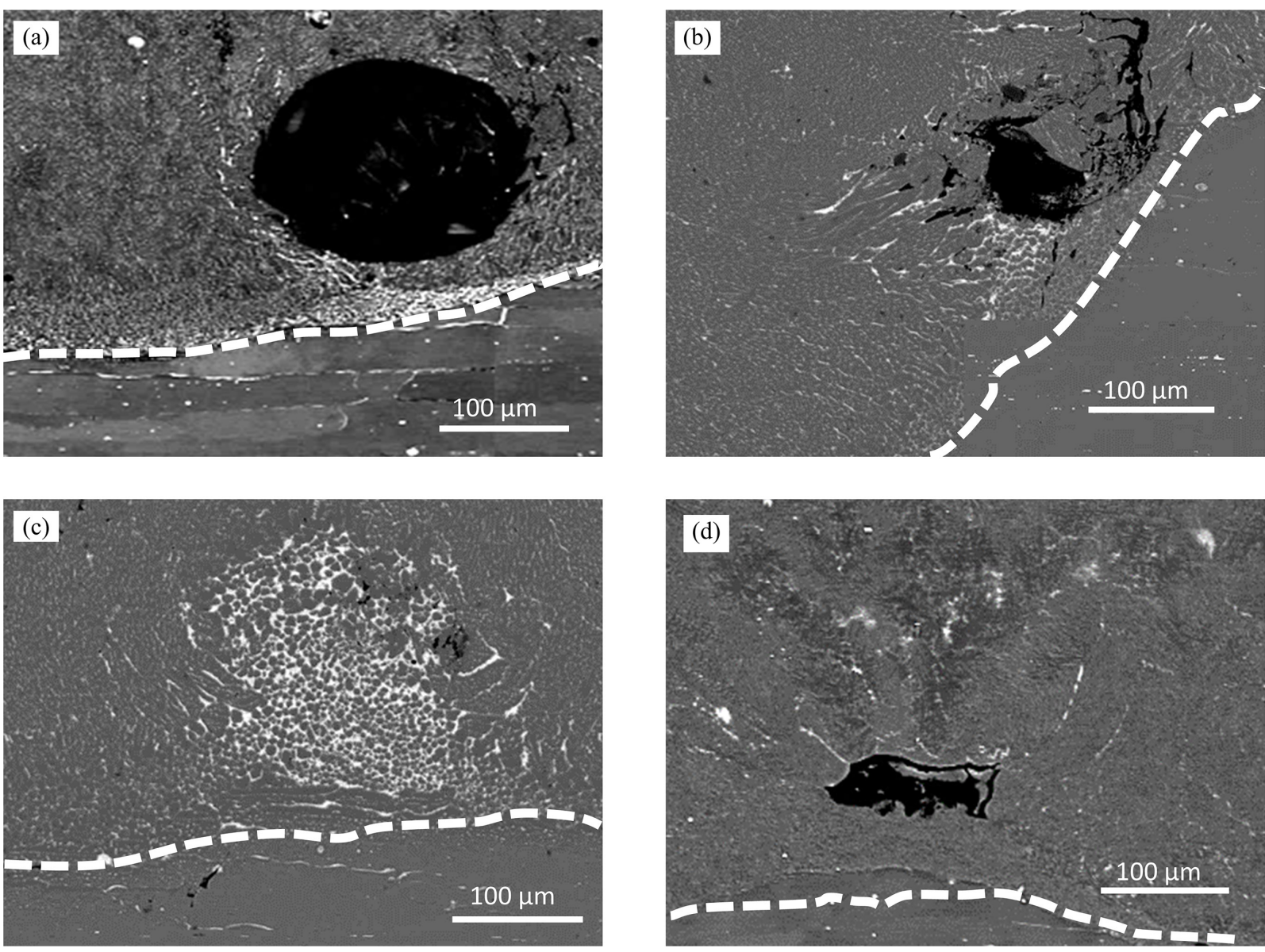

Figure 9: Typical porosities in laser pressure welds produced at varied parameters: (a) A porosity in weld produced at high heat input and low roller pressure; (b) A porosity in weld produced at high heat input and medium roller pressure; (c) A porosity in weld produced at high heat input and high roller pressure; (d) A porosity in weld produced at low heat input and high roller pressure.

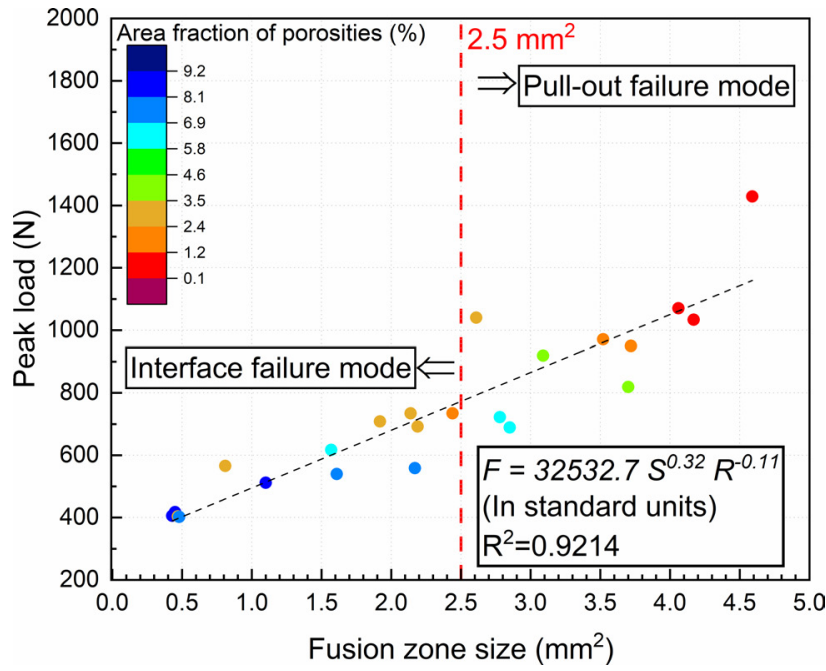

Figure 10: Effect of fusion zone size (S) and area fraction of porosities (P) on the peak load of tensile shear tests (F). conducted for the estimation of the peak load using the area fraction of porosity and fusion zone size (specified in SI unit).

$$
F=32532 S^{0.32} R^{-0.11}
$$

Where $F$ is the peak load of tensile shear test $(\mathrm{N}), S$ is the fusion zone size of laser pressure weld $\left(\mathrm{m}^{2}\right)$ and $R$ is the area fraction of porosity. The empirical equation suggests that the fusion zone size largely contributed to the peak load, compared to the area fraction of porosity. Moreover, fracture of the pull-out mode was initiated and preferentially propagated along the fusion boundary. Many studies [912, 22] on laser welded Al-Cu-Li alloys which reported the effect of local softening in the chill zone, support the failure mode which propagates along the fusion boundary. AA 2198, as a heat-treatable aluminum alloy, exhibits mechanical properties mainly dependent on the distribution and size of strengthening precipitates. The temper condition of the base material is T8 peak-aged, indicating the presence of high-density of strengthening precipitates distributed 
in the as-received base material [38-41]. The laser pressure welding process results in dissolution of strengthening precipitates and severest solute segregation in the chill zone. Therefore, the severe softening effect detected in the chill zone should be due to the loss of evaporated alloying elements, i.e., $\mathrm{Li}$ and $\mathrm{Mg}$, during laser welding $[22,36]$, the dissolution of the main strengthening precipitates, and the loss of solute atoms which leads to a lower volume fraction of reprecipitated strengthening precipitates during cooling, resulted from severe solute segregation into grain boundaries in the chill zone [22]. The precipitation behavior and the associated hardness in the laser pressure welded AA 2198 would be discussed in a separated paper.

\section{Conclusions}

Laser pressure welding successfully produced sound AlLi alloy 2198 weld with few porosities even without applying shielding gas. The fusion zone consisted of three microstructural zones, i.e., the chill zone, the columnar zone, and the equiaxed zone. Severe $\mathrm{Cu}$ segregation was detected in the chill zone. The fusion zone size increased with increasing welding heat-input; and increasing roller pressure also led to increased fusion zone size at high welding heat-input, possibly resulted from the re-melted alloy close to the fusion boundary due to the heat-dissipation promoted by the pressed rollers. The area fraction of porosities in the fusion zone decreased with increasing roller pressure and welding heat-input due to the elimination of porosities through mechanical pressing. The peak load of laser pressure welds during tensile shear testing increased with increasing fusion zone size. Two different fracture modes were detected in the tensile shear testing, i.e., the pull-out failure mode and the interface failure mode. Welds having the fusion zone area larger than 2.5 $\mathrm{mm}^{2}$ exhibited the pull-out mode. Fracture of the pull-out mode initiated and preferentially propagated along the fusion boundary due to the local softening resulted from severe $\mathrm{Cu}$ segregation.

Acknowledgement: The authors are grateful to Dr. Z. Liu for his helpful discussion. The authors would like to thank the Interdepartmental Doctoral Degree Program for Multidimensional (MD) Materials Science Leaders, Tohoku University Program for Leading Graduate Schools for the scholarships granted. The authors also acknowledge funding from National Natural Science Foundation of China [Grant No. 51475011].

\section{References}

[1] Lavernia, E. J., and N. J. Grant. Aluminium-lithium alloys. Journal of Materials Science, Vol. 22, No. 5, 1987, pp. 1521-1529.

[2] Driver, J. H., B. Dubost, F. Durand, R. Fougeres, P. Guyot, P. Sainfort and M. Suery, Mater. Sci. Forum, Vol. 217-222, 1996, pp. 647-652.

[3] Xiao, R., and X. Zhang. Problems and issues in laser beam welding of aluminum-lithium alloys. Journal of Manufacturing Processes, Vol. 16, No. 2, 2014, pp. 166-175.

[4] Chaturvedi, M. C. Laser welding of metals for aerospace and other applications. Welding and Joining of Aerospace Materials. Elsevier, 2011, pp. 75-79.

[5] Hou, K. H., and W. A. Baeslack III. Effect of solute segregation on the weld fusion zone microstructure in $\mathrm{CO} 2$ laser beam and gas tungsten arc welds in Al-Li-Cu alloy 2195. Journal of Materials Science Letters, Vol. 15, No. 3, 1996, pp. 208-213.

[6] Zuo, T. C. Laser materials processing of high strength aluminum alloys. National Defense Industry Press, Beijing, 2008.

[7] Xiao R. S., W. X. Yang, and K. Chen. Porosity characterization in laser welds of Al-Li alloy 1420. Appl Laser, Vol. 27, 2007, pp. 13-17.

[8] Whitaker, I. R., D. G. McCartney, N. Calder, and W. M. Steen. Microstructural characterization of $\mathrm{CO} 2$ laser welds in the Al-Li based alloy 8090. Journal of Materials Science Letters, Vol. 28, No. 20, 1993, pp. 5469-5478.

[9] Dittrich, D., J. Standfuss, J. Liebscher, B. Brenner, and E. Beyer. Laser Beam Welding of Hard to Weld Al Alloys for a Regional Aircraft Fuselage Design - First Results. Physics Procedia, Vol. 12, 2011, pp. 113-122.

[10] Yang W. X., X. Y. Zhang, and R. S. Xiao. Dual-beam laser welding of T-joint of aluminum-lithium alloy 2060-T8/2099-T83. Chinese Journal of Lasers, 40 (2013), id. 0703001.

[11] Lu, J., L. Chang, S. Wu, and S. Yin. Dendritic Boundary Corrosion of AA2198 Weld Using Fiber Laser Welding with Al-Cu Filler Wire. Acta Metallurgica Sinica (English Letters), Vol. 31, 2018, pp. 735741

[12] Liu, F., B. Zhou, Y. Mao, C. Huang, Y. Chen, and Z. Wang. Microstructure and mechanical properties of laser welded joints between 2198/2060 Al-Li alloys. Materials Science and Technology, Vol. 34, No. 1, 2018, pp. 111-122.

[13] Enz, J., C. Carrarin, S. Riekehr, V. Ventzke, and N. Kashaev. Hot cracking behaviour of an autogenously laser welded Al-Cu-Li alloy. Int. J. Manuf. Tech., Vol. 95, No. 1-4, 2018, pp. 299-310.

[14] Canaby, J. L., F. Blazy, J. F. Fries, and J. P. Traverse. Effects of high temperature surface reactions of aluminium-lithium alloy on the porosity of welded areas. Materials Science and Engineering A, Vol. 136, 1991, pp. 131-139.

[15] Pickens, J. R. The weldability of lithium-containing aluminium alloys. Journal of Materials Science, Vol. 20, No. 12, 1985, pp. 4247-4258.

[16] Zhang, X., W. Yang, and R. Xiao. Microstructure and mechanical properties of laser beam welded Al-Li alloy 2060 with Al-Mg filler wire. Materials \& Design, Vol. 88, 2015, pp. 446-450.

[17] Spold, G., R. Rothe, and K. Teske: Proc. Int. Congr. on Laser advanced materials processing, Osaka, Japan, May 1987, High Temperature Society of Japan, 1987, pp. 151-156.

[18] Nishimoto, K., H. Fujii, and S. Katayama. Laser pressure welding of Al alloy and low C steel. Science and Technology of Welding 
and Joining, Vol. 11, No. 2, 2006, pp. 224-231.

[19] Zhang, J., T. Huang, S. Mironov, Q. Wu, Q. Zhang, J. Xu and R. Xiao, Microstructure evolution during laser pressure welding of pure aluminum. Manuscript submitted for publication. https://doi.org/10.1016/j.matlet.2019.126931.

[20] Ghomashchi, M. R., and A. Vikhrov. Squeeze casting: An overview. Journal of Materials Processing Technology, Vol. 101, No. 1-3, 2000, pp. 1-9.

[21] Ilkhchy, A. F., M. Jabbari, and P. Davami. Effect of pressure on heat transfer coefficient at the metal/mold interface of A356 aluminum alloy. International Communications in Heat and Mass Transfer, Vol. 39, 2012, pp. 705-712.

[22] Hu, Y., S. Wu, and L. Chen. Review on failure behaviors of fusion welded high-strength Al alloys due to fine equiaxed zone. Engineering Fracture Mechanics, Vol. 208, 2019, pp. 45-71.

[23] Gallerneault, M., G. Durrant, and B. Cantor. The squeeze casting of hypoeutectic binary Al-Cu. Metallurgical and Materials Transactions. A, Physical Metallurgy and Materials Science, Vol. 27A, No. 12, 1996, pp. 4121-4132.

[24] Shehata, F. Squeeze casting of Al-Cu and Al-Si alloys. Advanced Materials and Processes, Vol. 4, 1994, pp. 136-140.

[25] Balan, P., R. M. Pillai, K. G. Satyanarayana, and B. C. Pai. The Structure and Properties of Squeeze-cast Eutectic Al-Si Plates. International Journal of Cast Metals Research, Vol. 6, No. 3, 1993, pp. 131-136.

[26] Skolianos, S. M., G. Kiourtsidis, and T. Xatzifotiou. Effect of applied pressure on the microstructure and mechanical properties of squeeze-cast aluminum AA6061 alloy. Materials Science and Engineering A, Vol. 231, No. 1-2, 1997, pp. 17-24.

[27] Lee, G. C., K. H. Baik, B. T. Lee, and K. S. Han. Study of squeeze casting conditions and microstructure in pure aluminium. $R e$ search Institute of Industrial Science and Technology, Pohang City. Technical Res. Rep., Vol. 4, No. 3, 1990, pp. 191-198.

[28] Kamio, A., H. Tezuka, and K. Takagi. Structures and Mechanical Properties of Squeeze-Cast Al-Li Alloys. The Light Metal Education Foundation, Chou-ku, Osaka, Japan, 1990, p. 541.

[29] Sun, X., E. V. Stephens, and M. A. Khaleel. Effects of fusion zone size and failure mode on peak load and energy absorption of advanced high strength steel spot welds under lap shear loading conditions. Engineering Failure Analysis, Vol. 15, No. 4, 2008, pp. 356-367.

[30] Pereira, A. M., J. M. Ferreira, A. Loureiro, J. D. M. Costa, and P. J. Bártolo. Effect of process parameters on the strength of resistance spot welds in 6082-T6 aluminium alloy. Materials \& Design, Vol. 31, No. 5, 2010, pp. 2454-2463.

[31] Rudy, J. F., and E. J. Rupert. Effects of Porosity on Mechanical Properties of Aluminum Welds. Welding Journal, Vol. 49, 1949, pp. 322-336.
[32] Ashton, R. F., R. P. Wesley, and C. R. Dixon. The Effect of Porosity on 5086-H116 Aluminum Alloy Welds. Welding Journal, Vol. 54, 1975, pp. 95-98.

[33] Molian, P. A., and T. S. Srivatsan. Weldability of aluminiumlithium alloy 2090 using laser welding. Journal of Materials Science, Vol. 25, No. 7, 1990, pp. 3347-3358.

[34] Lin, D., G. Wang, and T. S. Srivatsan. A mechanism for the formation of equiaxed grains in welds of aluminum-lithium alloy 2090. Materials Science and Engineering A, Vol. 351, No. 1-2, 2003, pp. 304-309.

[35] Reddy, G. M., A. A. Gokhale, K. S. Prasad, and K. P. Rao. Chill zone formation in $\mathrm{Al}-\mathrm{Li}$ alloy welds. Science and Technology of Welding and Joining, Vol. 3, No. 4, 1998, pp. 208-212.

[36] Han, B., Y. Chen, W. Tao, Z. Lei, H. Li, S. Guo, and P. Li. Nanoindentation investigation on the local softening of equiaxed zone in 2060-T8/2099-T83 aluminum-lithium alloys T-joints welded by double-sided laser beam welding. Journal of Alloys and Compounds, Vol. 756, 2018, pp. 145-162.

[37] Hong, C. P., H. F. Shen, and I. S. Cho. Prevention of macrosegregation in squeeze casting of an Al-4.5 wt pct Cu alloy. Metallurgical and Materials Transactions. A, Physical Metallurgy and Materials Science, Vol. 29A, No. 1, 1998, pp. 339-349.

[38] DuPont, J. N. Fundamentals of weld solidification. Welding Fundamentals and Processes, Vol. 6A, 2011, pp. 96-111.

[39] Rai, R., J. W. Elmer, T. A. Palmer, and T. DebRoy. Heat transfer and fluid flow during keyhole mode laser welding of tantalum, Ti-6Al-4V, 304L stainless steel and vanadium. J. Phys. D, Vol. 40, No. 18, 2007, pp. 5753-5766.

[40] Zhang, Z., X. Yang, J. Zhang, G. Zhou, X. Xu, and B. Zou. Effect of welding parameters on microstructure and mechanical properties of friction stir spot welded 5052 aluminum alloy. Materials \& Design, Vol. 32, No. 8-9, 2011, pp. 4461-4470.

[41] Reddy, G. M., A. A. Gokhale, and K. P. Rao. Weld microstructure refinement in a 1441 grade aluminum-lithium alloy. Journal of Materials Science, Vol. 32, No. 15, 1997, pp. 4117-4126. 